\title{
Zoonoses in the European Union: origin, distribution and dynamics - the EFSA-ECDC summary report 2009
}

A Lahuerta (angela.lahuerta@ecdc.europa.eu) ${ }^{1}$, T Westrell ${ }^{1}$, J Takkinen ${ }^{1}$, F Boelaert $^{2}$, V Rizzi ${ }^{2}$, B Helwigh ${ }^{3}$, B Borck ${ }^{3}$, H Korsgaard 3 , A Ammon ${ }^{1}$, P Mäkelä̈

1. European Centre for Disease Prevention and Control (ECDC), Stockholm, Sweden

2. European Food Safety Authority (EFSA), Parma, Italy

3. Technical University of Denmark, National Food Institute (DTU-FOOD), Copenhagen, Denmark

Citation style for this article:

Lahuerta A, Westrell T, Takkinen J, Boelaert F, Rizzi V, Helwigh B, Borck B, Korsgaard H, Ammon A, Mäkelä P. Zoonoses in the European Union: origin, distribution and dynamics - the EFSA-ECDC summary report 2009. Euro Surveill. 2011;16(13):pii=19832. Available online: http://www.eurosurveillance.org/ViewArticle.

aspx?Articleld $=19832$

Article published on 31 March 201

We present a summary of the main findings of the latest report of the European Food Safety Authority and European Centre for Disease Prevention and Control on zoonoses, zoonotic agents and food-borne outbreaks in the European Union (EU), based on data from 2009. Zoonoses are prevalent and widely distributed across several countries in the EU. The most important highlight of this report was the continuous decrease of human salmonellosis since 2005, probably due to effective control programmes in livestock.

\section{Background}

The European Union summary report on trends and sources of zoonoses, zoonotic agents and food-borne outbreaks in 2009, produced by the European Food Safety Authority (EFSA) and the European Centre for Disease Prevention and Control (ECDC) on 22 March 2011, describes the five-year trends (2005-2009) and occurrence of zoonotic infections and agents in humans, animals and foodstuffs in the 27 European Union (EU) Member States. Reported cases from countries of the European Economic Area (EEA)/ European Free Trade Association (EFTA), namely Iceland, Liechtenstein, Norway and Switzerland [1] are also included in the preliminary description but not in further analysis or trends.

Zoonoses are diseases that are transmissible between animals and humans. Humans can acquire these infections directly from contact with sick or carrier animals, or through the ingestion of contaminated foodstuffs or from other environmental sources. The severity of these diseases in humans can vary from mild symptoms to chronic sequelae or life-threatening conditions.

In order to prevent zoonoses from occurring in humans and to control such diseases, it is important to identify which animals and foodstuffs are the main sources of the infections. Thorough analysis and description of the distribution of zoonotic diseases among EU countries allows targeting of control measures and monitoring of the progress of food-safety policies in the EU. The annual EU summary report compiles information from human surveillance systems and from monitoring programmes for food and animals, with the aim of protecting human and animal health according to the Zoonoses Directive 2003/99/EC [2].

Assisted by the Zoonoses Collaboration CentreTechnical University of Denmark (ZCC-DTU), EFSA and ECDC jointly analysed the data and a summary of the main findings are presented in this article.

\section{Trends in the main zoonoses and zoonotic agents}

\section{Campylobacteriosis}

In 2009, as in the previous four years, campylobacteriosis was the most commonly reported zoonotic disease in humans (198,252 confirmed cases). There was a $4 \%$ increase in the number of reported cases compared with 2008 . The notification rate was 45.6 cases per 100,000 population, with children aged under five years having the highest notification rate (128 cases per 100,000 population). The number of reports of human campylobacteriosis was stable over the five-year period, but the incidence was always higher during the summer months. This could be due to a seasonal effect that has not been addressed through traditional Campylobacter control programmes for food and animals.

In foodstuffs, as in previous years, Campylobacter was most commonly isolated from fresh broiler meat at different stages of production: $31 \%$ of samples $(n=7,312)$ were positive. According to the recent scientific opinion of EFSA biological hazards panel, about $20-30 \%$ of human campylobacteriosis cases can be attributed to the consumption and handling of chicken meat [3]. In pig meat samples, Campylobacter was detected much less frequently $(0.6 \%, n=1,006)$ than in broiler meat. However, there was high variability in the number of reporting countries and sample size, depending on animal species and type of meat.

C. jejuni was the most frequently reported species in humans as well as in poultry and cattle, while $C$. coli 
was less prevalent in humans and was isolated mainly from pigs.

\section{Salmonellosis}

Salmonellosis was the second most commonly reported zoonotic infection in humans in 2009 , with 108,614 confirmed cases reported and a notification rate of 23.7 cases per 100,000 population, which is $17 \%$ less than in 2008. There has been a statistically significant decreasing trend in the notification rate during 2005 to 2009 , with a mean reduction of $12 \%$ per year. The decrease has been particularly sharp for the most commonly reported serovar in humans, Salmonella Enteritidis: notifications fell by $24 \%$ from 2008 to 2009. The second most common serovar, S. Typhimurium, was also reported less frequently in 2009 compared with 2008 , presenting a decrease of $10 \%$.

In food, Salmonella was the most commonly identified pathogen in fresh poultry and fresh pork meat, where $8.7 \%(n=30,544)$ and $0.7 \%(n=83,797)$ of samples were found positive, respectively. The bacterium was rarely detected in vegetables, fruit or dairy products.

Harmonized Salmonella EU control programmes in poultry have been implemented progressively since 1994, starting with primary production. In 2009, Member States had to meet the EU reduction target of having $\leq 1 \%$ of breeding flocks of Gallus gallus (chickens) infected with the five target serovars (S. Enteritidis, S. Typhimurium, S. Hadar, S. Infantis and S. Virchow) $[4,5]$. Control efforts at poultry-farm level in Member States are considered to have contributed remarkably to a positive public-health effect in reducing the number of reported human salmonellosis cases.

It is reassuring that the declining trend of human salmonellosis continued in 2009. This is likely to be the result of intensified control programmes of Salmonella in animal reservoirs, particularly in poultry, and better hygiene practices throughout the food production chain. The introduction of molecular surveillance at the EU level in the future will provide more clues about the importance of different animal and food sources of infection and the impact of Salmonella control programmes in livestock.

\section{Yersiniosis}

The number of reported human cases of yersiniosis in 2009 was 7,595, with a notification rate of 1.65 cases per 100,000 population. Although the notification rate decreased significantly ( $p<0.01$ ) since 2005 (2.6 cases per 100,000 population), the disease continues to be the third most frequently reported zoonosis in the EU.

In animals, Yersinia spp. were reported mainly in pigs and pork products. Yersinia enterocolitica was isolated from $4.8 \%$ of pork samples $(n=2,134)$.

\section{Listeriosis}

In 2009, the notification rate of human listeriosis was 0.36 cases per 100,000 population. The number of confirmed cases increased by $19 \%$ in $2009(n=1,645)$ compared with $2008(n=1,381)$. Listeriosis is an important food-borne disease due to its severity: it can lead to a high risk of abortion in pregnant women and high levels of mortality in elderly people (a case fatality rate of $19 \%$ was reported in people aged 65 years and over). The highest notification rate was also reported in this age group (1.1 cases per 100,000 population), representing $59 \%$ of all reported cases. Only $4.2 \%$ of the reported cases were detected among children aged under five years.

Foodstuffs that are considered the main source of Listeria in the EU include ready-to-eat (RTE) products (fish and meat) and soft cheeses. According to the EU microbiological criteria, foodstuffs that contain less than 100 colony-forming units $(\mathrm{cfu}) / \mathrm{g}$ of L. monocytogenes at the retail level are considered acceptable for human consumption [6]. In 2009, the highest proportions of non-compliant food products at retail level were found in RTE fish products, cheese (especially soft and semi-soft) and RTE products of meat origin, although the level was lower than in the previous two years.

The high proportion of deaths among elderly people as a result of Listeria infection is of particular concern. An EFSA-ECDC collaboration on typing of Listeria in RTE products and clinical cases of human listeriosis started in 2010 and continues to 2012 . The results provided by this study will contribute to a better understanding of listeriosis epidemiology in the EU and should help to target effective control and preventive measures within both food safety and public health.

\section{Verotoxigenic Escherichia coli \\ (VTEC) infection}

A total of 3,573 confirmed human cases of verotoxigenic E. coli (VTEC) infection ( 0.75 cases per 100,000 population) were reported in 2009 , a $13 \%$ increase compared with $2008(n=3,159)$. The notification rate has increased since 2007 (0.6 cases per 100,000 population). VTEC 0157 was again the serotype most commonly reported, although VTEC isolates were not characterised at the serotype level in $28 \%$ of the cases in 2009. As in previous years, the notification rate was highest in children aged $0-4$ years. A considerable increase (of $66 \%$ ) in the number of reported cases who developed haemolytic uremic syndrome was detected in $2009(n=242)$ compared with $2008(n=146)$, occurring mainly among 0-4 year-olds. Several outbreaks of VTEC infection were detected in United Kingdom and the Netherlands in 2009 and have contributed to the increasing trend in Europe and increased the number of haemolytic uremic syndrome cases [7-9]

In animals, VTEC was mainly isolated from cattle and, to a lesser extent, from small ruminants such as sheep and goats. In food, VTEC was detected mainly in meat 
from ruminants: $3.2 \%(n=248)$ of sheep meat samples, followed by $2.3 \%(n=9,285)$ of bovine meat samples. It was also isolated from raw cow's milk. The reported occurrence of VTEC bacteria in food was generally low, and the levels have been relatively constant between 2005 and 2009.

\section{$Q$ fever}

A total of 1,987 confirmed human cases of $Q$ fever were reported in 2009, representing a $25 \%$ increase compared with $2008(n=1,594)$. However, the majority of cases ( $91 \%)$ was detected in two countries: the Netherlands $(n=1,623)$ and Germany $(n=190)$. Adults aged $45-64$ years had the highest notification rate (1.2 cases per 100,000 population).

The continued increase in Q fever in 2009 was the result of several outbreaks in which people were exposed to infected sheep and goats, mainly in the Netherlands.

\section{Trends in zoonotic parasitic diseases and zoonotic parasites \\ Trichinellosis}

Reported cases of human trichinellosis increased by $12 \%$ in $2009(n=748)$ compared with $2008(n=670)$. The distribution of reported cases was not homogeneous across EU Member States, as the majority of cases (94\%) was reported by four eastern European countries (Bulgaria, Romania, Poland and Lithuania). The reason for this large proportion of human cases in these countries may be linked to particular regional habits, such as raising pigs in backyards for private consumption, for which official meat inspection for the presence of Trichinella spp. is not carried out.

The increased number of cases of trichinellosis in these countries is of major concern because the disease is easily preventable when appropriate veterinary meat inspection is carried out and preventive measures are taken.

\section{Echinococcosis}

There were 790 reported human cases of echinococcosis in 2009, which is $11 \%$ fewer than in $2008(n=891)$. Among reported cases with a known species, the predominant species was still $E$. granulosus (77\%) while E. multilocularis was reported three times less frequently.

In animal populations, 18 Member States submitted data on Echinococcus spp. found in domestic livestock (cattle, pigs, sheep, goats and solipeds) as part of routine screening at slaughter. In addition, 10 Member States reported data on foxes positive for $E$. multilocularis (15.6\% of tested foxes carried this species). Control measures implemented for dogs, such as deworming treatment, can restrict the spread of echinococcosis. However, foxes remain a potential source of exposure and vehicle for spread in some EU countries.

\section{Toxoplasmosis}

In 2009, a total of 1,259 confirmed human cases of toxoplasmosis were reported. The highest proportion was recorded in women aged $24-44$ years, probably due to routine screening for antibodies against Toxoplasma during pregnancy.

Sheep and goats were the animal species with the highest proportion of Toxoplasma-positive samples reported $(24.4 \%, n=4,217)$.

\section{Trends in other zoonoses:}

\section{brucellosis, tuberculosis due to}

\section{Mycobacterium bovis and rabies}

In 2009, human cases of brucellosis $(n=401)$ decreased by $35.2 \%$ compared with $2008(n=619)$. The number of cases has been decreasing significantly ( $p<0.01)$ in the EU since 2005 .

Cases of human tuberculosis due to Mycobacterium bovis in 2009 were not reported to the European Surveillance System (TESSy) at the time of the report production. Therefore the trends and epidemiological analysis were based on 2008 data. The number of confirmed human cases of tuberculosis due to $M$. bovis increased in the EU by $7.5 \%$ in $2008(n=115)$ compared with $2007(n=108)$. However, this could be a normal variation in the disease occurrence. Overall, the numbers of human cases decreased during the previous four years, mainly due to effective disease eradication programmes implemented by Member States in cattle herds.

In 2009, one indigenous case of rabies - in a woman bitten by a rabid fox - was reported in Romania. This is the second autochthonous case of rabies that occurred in Romania in the previous two years.

\section{Conclusion}

In 2009, campylobacteriosis, salmonellosis and yersiniosis were the most commonly reported zoonotic infections in humans of those monitored for this report in the EU, as in previous years. Parasitic zoonoses trichinellosis, echinococcosis and toxoplasmosis - are still present in the EU. While some diseases, such as salmonellosis, have continued to decline, probably due to effective EU control measures in animal reservoirs, others have increased considerably, such as trichinellosis, even though the disease can be easily prevented.

The results of this report highlight the importance of close collaboration between veterinarians and public health specialists and the need for robust surveillance systems, in the animal/food sector and in humans, in order to monitor the impact of EU-wide control measures, detect emerging trends and sources and unexpected changes in the disease dynamics of zoonoses in Europe. 


\section{References}

1. European Food Safety Authority (EFSA), European Centre for Disease Prevention and Control (ECDC). The European Union summary report on trends and sources of zoonoses, zoonotic agents and food-borne outbreaks in 2009; EFSA Journal. 2011; 9(3):2090. EU. Available from: http://www.efsa.europa.eu/fr/ efsajournal/pub/2090.htm

2. Directive $2003 / 99 / E C$ of the European Parliament and of the Council of 17 November 2003 on the monitoring of zoonoses and zoonotic agents, amending Council Decision 90/424/ EEC and repealing Council Directive 92/117/EEC. Luxembourg: Publications Office of the European Union. 12.12.2003: L 325/31. Available from: http://eur-lex.europa.eu/LexUriServ/ LexUriServ.do?uri=0J:L:2003:325:0031:0040:EN:PDF

3. EFSA Panel on Biological Hazards (BIOHAZ). Scientific opinion on quantification of the risk posed by broiler meat to human campylobacteriosis in the EU. EFSA Journal. 2010;8(1):1437. Available from: http://www.efsa.europa.eu/en/efsajournal/ pub/1437.htm

4. European Commission. Commission Regulation (EC) No $1003 / 2005$ of 30 June 2005 implementing Regulation (EC) No $2160 / 2003$ as regards a Community target for the reduction of the prevalence of certain Salmonella serotypes in breeding flocks of Gallus gallus and amending regulation (EC) No 2160/2003. Luxembourg: Publications Office of the European Union. 1.7.2005:L 170/12.. Available from: http://eur-lex. europa.eu/LexUriServ/LexUriServ.do?uri=0J:L:2005:170:0012: 0017:EN:PDF

5. European Commission. Commission Regulation (EC) No $1168 / 2006$ of 31 July 2006 implementing Regulation (EC) No $2160 / 2003$ as regards a Community target for the reduction of the prevalence of certain salmonella serotypes in laying hens of Gallus gallus and amending regulation (EC) No 1003/2005. Luxembourg: Publications Office of the European Union.

1.8.2006:L 211/4. Available from: http://eur-lex.europa.eu/ LexUriServ/LexUriServ.do?uri=0]:L:2006:211:0004:0008:EN: PDF

6. European Commission. Commission regulation (EC) No $2073 / 2005$ of 15 November 2005 on microbiological criteria for foodstuffs. Luxembourg: Publications Office of the European Union. 22.12.2005:L 338/1. Available from: http://eur-lex. europa.eu/LexUriServ/LexUriServ.do?uri=0J:L:2005:338:0001 :0026:EN:PDF

7. Department for Environment, Food and Rural Affairs (Defra). Zoonoses report UK 2009. London: Defra; 2011. Health Protection Agency (HPA). Review of the major outbreak of E. coli $0_{157}$ in Surrey, 2009. Report of the Independent Investigation Committee June 2010. London: HPA; 2010. Available from: http://www.griffininvestigation.org.uk/report/ full_report.pdf

8. Health Protection Agency (HPA). Review of the major outbreak of E. coli $\mathrm{O}_{157}$ in Surrey, 2009. Report of the Independent Investigation Committee June 2010. London: HPA; 2010. Available from: http://www.griffininvestigation.org.uk/report/ full_report.pdf

9. Greenland K, de Jager C, Heuvelink A, van der Zwaluw K, Heck M, Notermans D, et al. Nationwide outbreak of STEC O157 infection in the Netherlands, December 2008-January 2009: continuous risk of consuming raw beef products. Euro Surveill. 2009;14(8): pii=19129. Available from: http://www. eurosurveillance.org/ViewArticle.aspx?Articleld=19129 